論文

\title{
$\mathrm{CDGPS}$ 를 위한 $\mathrm{LSAST}$ 미지정수 추정기법 개선에 관한 연구 \\ 이기훈*
}

\section{A study on improving LSAST ambiguity resolution for CDGPS}

Kihoon Lee*

\begin{abstract}
GPS, which has been opened to the public since the 1980's, uses the C/A code time of arrival to estimate the position, and measures the carrier doppler frequency to estimate the velocity. In development from the 1990's, DGPS has improved position accuracy by eliminating common errors and CDGPS has achieved cm-level position accuracy using carrier phase. In this paper, a modified LSAST ambiguity resolution method for CDGPS is proposed to improve reliability and computational efficiency. Also the test results of $\mathrm{cm}$ level relative positioning of a moving vehicle using single frequency GPS receivers are compared to INS position. This research result can be widely used for the development of high precision INS, unmanned autonomous driving, survey and mapping, etc.
\end{abstract}

\section{초 록}

1980년대부터 민간에 개방된 GPS는 C/A코드의 도달시간을 측정하여 위치를 계산하고, 반송파의 도플러 주파수를 측정하여 속도를 계산한다. 위치정확도를 향상시키기 위하여 공통오차를 제거하는 DGPS 기법과 반송파 위상을 이용하여 수 $\mathrm{cm}$ 내의 정확도를 가질 수 있는 CDGPS 기법이 1990년대부터 개발되기 시작하였다. 본 논문에서는 CDGPS를 위 해 LSAST 미지정수 추정기법을 개선하여 계산효율 및 신뢰도를 높이고, 단일 주파수 GPS 수신기를 이용하여 움직이는 항체의 상대위치를 수 $\mathrm{cm}$ 내의 정확도로 측정한 실험결 과를 INS의 위치와 비교하여 제시한다. 이러한 결과는 추후 정밀관성항법장치, 무인자율 주행, 측지 및 정밀지도제작 등에 유용하게 쓰일 수 있다.

Key Words : GPS(위성항법시스템), CDGPS(반송파 차분위성항법), INS(관성항법장치), LSAST (최소자승 미지정수추정), Ambiguity resolution(미지정수 추정기법)

\section{I. 서 론}

항체의 위치를 정밀하게 측정하기 위한 방법은 크게 관성항법과 전파항법으로 구분되는데, 중궤 도 위성을 이용하여 전천후로 전지구상에서 매우 정밀하게 위치를 측정할 수 있는 GPS(Global Positioning System)는 전파항법의 한 종류로 가

† 2006년 2월 8일 접수 2006년 4월 17일 심사완료

* 정회원, 국방과학연구소

연락저자, E-mail : kihoon@add.re.kr

대전시 유성우체국 사서함 35-4
용성 및 정확성이 우수하여 매우 다양하게 응용 되고 있다. DGPS(Differential GPS)는 위성신호 의 전송과정에서 유발되는 공통오차를 제거하여 위치정확도를 향상시킨 기법으로 2000년 이전의 SA(Selective Availability) 존재시 효과적이었다. 특히 수 $\mathrm{cm}$ 의 정확도로 위치를 측정할 수 있는 CDGPS(Carrier phase DGPS)는 측지를 비롯하여 정밀관성항법장치, 무인자율주행, 정밀지도, 지진 측정, 건물구조변형검출, 자세측정 등 매우 다양 한 응용분야를 가진다[1].

CDGPS는 GPS 위성에서 전송되는 $\mathrm{L}$ 밴드의 반 송파 위상을 정밀하게 측정하여 위치를 계산하는 
기법으로 미지정수가 존재하여 신뢰도 문제가 발 생한다. 이러한 미지정수를 효율적으로 구하기 위하여 오늘날까지 다양한 미지정수 추정기법이 제안되어 왔으며, 실시간으로 미지정수를 찾아서 위치를 계산하는 RTK(Real Time Kinematic) 기법이 개발되고 있다[2][3][4]. 본 논문에서는 CDGPS에 서 가장 중요한 미지정수 추정기법을 개선하여 신뢰도 및 연산효율을 높이고, GPS 수신기를 이 용하여 움직이는 항체의 상대위치를 수 $\mathrm{cm}$ 내의 정확도로 측정한 실험결과를 INS(Inertial Navigation System) 등으로 측정한 위치데이터와 비교하여 제시한다.

\section{CDGPS 개요}

\subsection{GPS 측정치}

GPS 수신기는 $20180 \mathrm{~km}$ 상공에 위치한 위성 신호를 이용하여 항체의 위치, 속도, 시각 등의 항법정보를 $\mathrm{ECEF}$ (Earth Centered Earth Fixed) 좌표계로 제공하고 있다. GPS 수신기에서는 이 러한 항법정보를 구하기 위해서 GPS 위성과 수 신기 안테나 사이의 거리에 시각오차 등이 포함 된 의사거리, 상대속도에 의해서 발생되는 도플 러 주파수, 도플러 주파수를 적분해가는 반송파 위상에 관한 정보를 측정한다. 각각의 GPS 위성 은 CDMA(Code Division Multiple Access) 방식 으로 변조되어서 전송되며, 그림 1 과 같이 의사 거리와 반송파 위상은 동일하게 위성으로부터 수 신기까지의 거리를 측정한다고 간주될 수 있다.

GPS 수신기에서 의사거리는 위성과 수신기의 거리 정보를 포함하는데 위성의 위치오차 $\left(\delta_{e p h}\right)$, 이온층 지연 $\left(\delta_{\text {iono }}\right)$, 대류권 지연 $\left(\delta_{\text {trop }}\right)$, 다중경로 $\left(\delta_{m p, c o d e}\right)$, 수신기 시각오차 $(T)$ 및 측정잡음 오차 $\left(\nu_{\text {code }}\right)$ 등을 포함하여 수식 (1)과 같이 표현된다.

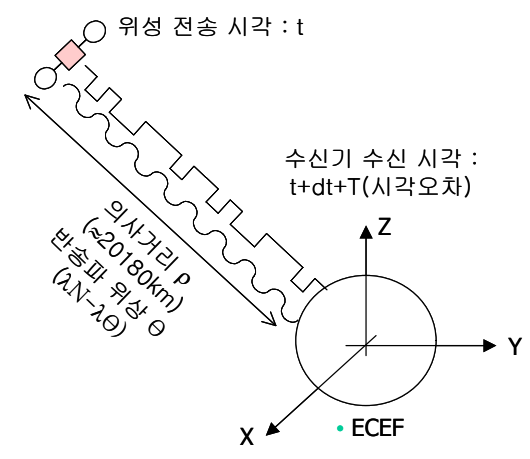

그림 1. 의사거리와 반송파 위상
또한 반송파 위상은 $1.57542 \mathrm{GHz}$ 의 반송파 주파 수 신호에서 순간적인 시각에 측정된 위상 값을 뜻하며, 수식 (2)와 같이 표현된다. 반송파 위상 은 의사거리와 비슷하나 이온층 앞섬이 있으며 한 파장의 길이인 약 $0.19 \mathrm{~m}$ 의 반복회수를 의미 하는 미지정수 $\mathrm{N}$ 이 존재한다.

$$
\begin{aligned}
& \rho=r+\delta_{\text {eph }}+\delta_{\text {iono }}+\delta_{\text {trop }}+\delta_{m p, \text { code }}-c T+v_{\text {code }} \\
& \lambda \theta=r+\delta_{\text {eph }}-\delta_{\text {iono }}+\delta_{\text {trop }}+\delta_{m p, \text { carrier }}-c T+v_{\text {carrier }}+\lambda N
\end{aligned}
$$

여기서, $r=$ 위성과 수신기간의 거리

$c=$ 광속

$\lambda=$ 반송파 파장

$\delta_{m p, \text { carrier }}=$ 반송파 다중경로 오차

$\nu_{\text {carrier }}=$ 반송파 측정잡음

미국의 GPS를 총괄하는 JPO 및 $\mathrm{DOD}$ 에서 제 안한 민간용(SPS) GPS 수신기의 의사거리 추정 오차는 $\mathrm{SA}$ 를 제외하면 $8 \mathrm{~m}$ 정도이다[5]. 따라서 위치정확도는 일반적으로 사용되는 $\mathrm{HDOP}=1.5$ 를 적용하면 수평정확도가 $12 \mathrm{~m} \mathrm{drms}$ 정도로 $\mathrm{SA}$ 가 있었던 2000년 이전의 공식 발표된 $100 \mathrm{~m}$ $2 \mathrm{drms}$ 에 비해 매우 작음을 알 수 있다[1]. 의사 거리는 위성으로부터 수신기까지의 도달시간 (Time Of Arrival)을 나타내는 C/A 코드로부터 측정되기 때문에 모호성을 가지지 않는데 반해 다중경로 $(1 \sigma 2.5 \mathrm{~m})$ 및 측정오차 $(1 \sigma 1.5 \mathrm{~m})$ 가 크다. 이에 비해 반송파 위상은 앞에서 살펴본 미지정 수 $\mathrm{N}$ 이 존재하는데 반해 다중경로(최대 $0.048 \mathrm{~m}$ ) 및 측정잡음 오차 $(1 \sigma 0.002 \mathrm{~m})$ 가 작다[6]. 반송파 위상의 다중경로 오차는 위상추적루프(PLL, Phase Lock Loop)에서 다중경로에 의해 최대로 발생할 수 있는 오차가 $90^{\circ}$ 이기 때문에 최대오차 가 $1 / 4$ 파장인 $0.048 \mathrm{~m}$ 이다. 또한 반송파 위상의 측정잡음은 약 $0.19 \mathrm{~m}$ 인 파장을 10 비트 이상의 해상도로 추적하기 때문에 매우 작다.

한편 의사거리 및 반송파 위상의 공통된 오차 인 위성의 위치오차, 이온층 오차, 대류권 지연오 차는 기준국과 이동국으로 구성된 DGPS(차분위 성항법) 방식으로 줄일 수 있다. DGPS를 적용하 면 위성 위치 오차는 제거되며, 이온층 오차, 대 류권 오차 및 다중경로는 안테나 사이의 거리에 반비례하여 감소하므로 상대위치 정확도는 단독 측위보다 향상된다.

\subsection{CDGPS 원리}

CDGPS는 반송파 위상의 차분을 이용하여 수 $\mathrm{cm}$ 이내의 정확도로 상대위치를 정확히 측정하 는 기법이다. 일반적으로 기준국과 이동국 GPS 수신기의 시각오차를 제거하기 위하여 이중차분 


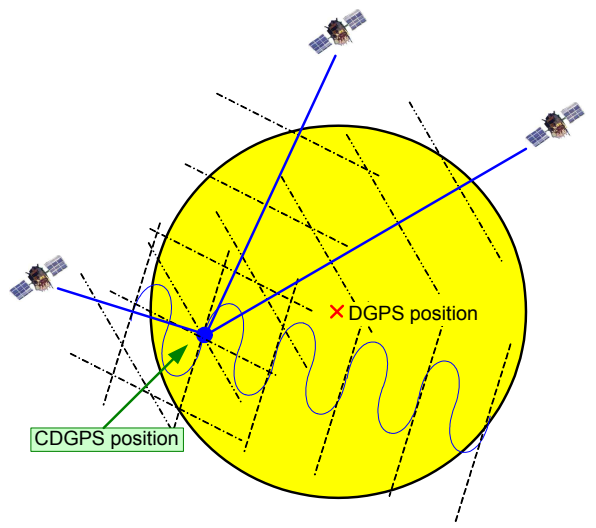

그림 2. 미지정수 검색범위

을 이용하는데 의사거리 및 반송파 위상의 이중 차분 측정치는 다음과 같다[8].

$$
\begin{aligned}
\nabla \Delta \rho= & \nabla \Delta r+\nabla \Delta \delta_{m p, \text { code }} \\
& +\nabla \Delta \nu_{\text {code }} \\
\nabla \Delta \lambda \theta= & \nabla \Delta r+\nabla \Delta \delta_{m p, \text { carrier }} \\
& +\nabla \Delta \nu_{\text {carrier }}+\nabla \triangle \lambda N
\end{aligned}
$$

여기서, $\nabla \Delta=$ 기준국과 이동국의 차분치를

위성간 차분하는 이중차분

위 수식에서 알 수 있듯이 대부분의 오차는 제거되며, 측정잡음은 이중차분하기 때문에 커진 다고 할 수 있으나, 수식 (4)의 반송파 위상 측정 식에서 미지정수 $\mathrm{N}$ 을 추정하면 $\mathrm{r}$ 로 표현되는 상 대위치는 매우 정확하게 계산된다. CDGPS는 일 반적으로 그림 2 와 같이 의사거리 차분을 이용하 여 개략적인 위치를 구하고 오차범위를 지정한 다음, 오차범위 내에서 미지정수 $\mathrm{N}$ 을 추정하여 반송파 위상 측정치로써 상대위치를 정확하게 계 산한다. 그림 2에서 반송파 위상은 $0.1902 \mathrm{~m}$ 마다 같은 값을 측정하기 때문에 모호성이 존재하고, 참값의 상대위치에서는 반송파 위상의 잔차 (Residuals)가 매우 작다. 대부분의 미지정수 추 정기법은 반송파 위상의 잔차 특성을 이용하여 미지정수를 추정한다. 다음 장에서는 위와같이 CDGPS에서 필수적인 미지정수 추정기법을 고찰 하고, 기존의 미지정수 추정기법을 개선하여 신 뢰도 및 연산효율 향상 효과를 살펴본다.

\section{III. 미지정수 추정기법 개선}

\section{1 기존 미지정수 추정기법}

반송파 위상을 이용하여 매우 정밀한 위치를 구하기 위해서는 앞장에서 살펴본 바와 같이 미
지정수 $\mathrm{N}$ 을 추정해야 한다. 기준국과 이동국으 로 이루어진 CDGPS에서 이동국의 상태에 따라 다양한 미지정수 추정기법이 개발되어 왔다. 이 동국이 정지상태에 있다면, 위성의 기하학적인 변화에 따라 미지정수는 역으로 계산되어 참값으 로 수렴하며, 이동국의 위치는 수렴한 미지정수 를 이용하여 계산될 수 있다. 또한 이동국이 기 준국과 가깝다면 안테나 위치를 서로 바꾸어 미 지정수를 계산하는 안테나 교환(Antenna Swap) 기법도 개발되었다[6]. 최근에는 GPS 수신기에 가까운 의사위성(Pseudolite)을 이용하여 기하학 적인 변화를 크게함으로써 미지정수 추정 성공률 을 높이는 방안도 연구되고 있다[7].

대부분의 미지정수 추정기법은 추정된 정수 값에 따른 잔차 등으로 구성된 비용함수(Cost Function)를 최소화시키는 미지정수를 확정한다. 특히 이동국이 움직이는 항체에 대해서 적합한 미지정수 추정기법은 1990년 Hatch에 의해 발표 된 LSAST(Least Squares Ambiguity Search Technique) 기법으로 미지정수 추정범위를 상당 히 감소시켜 실시간성능을 향상시킨 것으로 요약 하면 다음과 같다[2].

- 4 개의 주위성과 나머지의 부위성으로 구분

- 개략적 위치와 오차 범위를 정함

- 주위성의 미지정수를 생성하고 위치를 구함

- 각 위치에 대해 부위성 정수여부를 판단

위와 같은 LSAST 기법은 위치를 구하기 위해 필요한 위성은 4 개이며 나머지는 여유분인 특징 을 이용한 것이다. Teunissen에 의해서 발표된 LAMBDA (Least-squares Ambiguity Decorrelation Adjustment) 기법은 서로 상관되어 있는 이중차 분 측정치의 상관특성을 약화시키고, 잔차로부터 구해지는 비용함수를 최소화시키는 미지정수를 구 할 때 부피유지변환(Volume Preserving Transformation) 함수를 이용하여 미지정수 확정의 신뢰도를 높여 준다[3].

\section{2 제안한 미지정수 추정기법}

본 논문에서는 Hatch에 의해 제안된 LSAST 기법을 개선하여 실시간 관점에서 미지정수 확정 의 신뢰도를 높이고 연산효율을 향상시킨다.

제안한 미지정수 추정기법은 그림 3 과 같은 흐름도를 가진다. 먼저 DGPS를 이용하여 개략적 인 위치와 오차범위를 설정하고(Define search space), 4 6개의 주위성을 선택하여 이중차분 측 정치 3 개에 대한 미지정수 후보군을 정의한다 (Define 4 6 primary sat). 다음으로 각각의 미지 정수 후보군에 대하여 위치를 구한다음 부위성에 


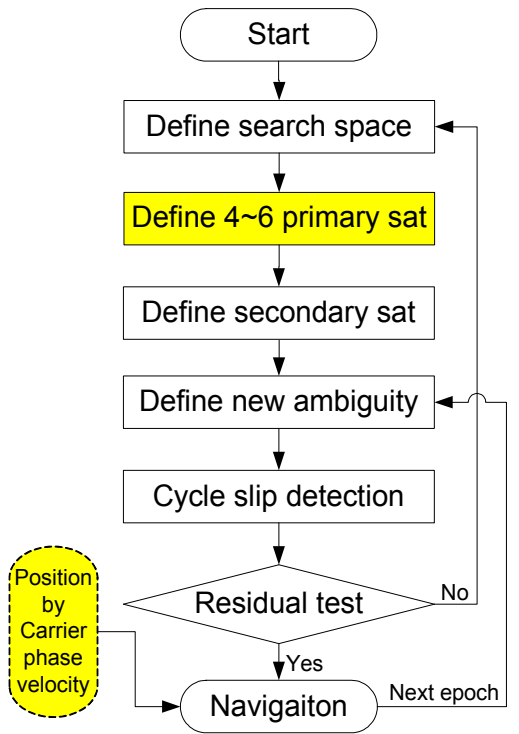

그림 3. 제안한 미지정수 추정기법

대한 미지정수를 계산하여 모든 위성으로 다시 위치를 계산한다(Define secondary sat). 미지정 수는 해당 위성을 연속적으로 추적하는 한 변하 지 않기 때문에 여러번 측정한 잔차의 크기 및 다른 미지정수와의 잔차비율을 분석하여 미지정 수를 확정한다(Residual test). 이후 위치를 계산 한다(Navigation). 다음 순간에 새로운 위성이 추 적되면 기존 위성의 확정된 미지정수로써 위치를 계산하고, 새로운 위성에 대한 미지정수를 계산 한다(Define new ambiguity). 또한 미지정수가 불안정한 신호추적에 의해 변할 수 있으므로 모 든 위성에 대한 Cycle slip 여부를 검출하는 과 정이 필요하다(Cycle slip detection). 특히 본 논 문에서는 CDGPS에 의한 위치를 재검증하기 위 해 이동국 단독으로 매우 정확하게 측정되는 평 균속도를 적분하여 얻어지는 위치를 사용한다.

Hatch의 LSAST 기법은 4 개의 주위성을 선택 하여 미지정수 후보군을 생성한다. LSAST는 위 성신호 세기가 크고 다중경로 오차가 작은 높은 앙각의 위성을 4 개 선택하는데, 실제 반송파 위 상의 측정오차를 분석한 결과 앙각에 따른 오차 의 반비례 관계는 미미하고, 모든 위성이 안테나 위상중심 흔들림의 영향을 크게 받는다[9]. 단지 저앙각 위성의 경우 지표면의 장애물에 의해서 연속적인 신호추적이 어려울 수 있다. 본 논문에 서는 기준값 $\left(20^{\circ}\right)$ 이상의 앙각을 가지는 위성에 대해서 최소사이각을 가지는 4 6개의 주위성을 선택하여 3 개의 이중차분 측정치를 생성하는 미 지정수 추정기법을 제안한다. 즉 1 개의 이중차분
측정치를 얻기 위해서는 2 개의 위성이 필요한데, 모든 위성의 사이각을 구하여 가장 작은 사이각 3 개를 선택하여 주위성으로 선택한다. 따라서 주 위성은 최소 4 개에서 최대 6개가 선택된다.

주위성의 최소사이각 선택효과를 알아보기 위 해, 미지정수 추정범위인 그림 4 의 원내 $\left(\vec{e}_{d b}\right)$ 에서 주위성의 이중차분 측정치를 구하면 위성 $k, l$ 에 대한 단일 차분인 수식 (5), (6)을 차분한 수식 (7)과 같이 표현된다.

$$
\begin{aligned}
\theta_{d b}^{k}= & N_{d b}^{k}+\delta \theta_{d b}^{k} \\
= & 1_{d}^{k} \cdot \vec{e}_{d b}=|e| \cos \left(\phi_{k}-\phi_{b}\right) \\
\theta_{d b}^{l}= & N_{d b}^{l}+\delta \theta_{d b}^{l} \\
= & 1_{d}^{l} \cdot \vec{e}_{d b}=|e| \cos \left(\phi_{l}-\phi_{b}\right) \\
\theta_{d b}^{k l}= & N_{d b}^{k l}+\delta \theta_{d b}^{k l} \\
= & |e|\left(\cos \left(\phi_{k}-\phi_{b}\right)-\cos \left(\phi_{l}-\phi_{b}\right)\right) \\
= & -2|e| \sin \left(\phi_{k}-\phi_{b}+\Delta \phi / 2\right) \\
& \times \sin (\Delta \phi / 2)
\end{aligned}
$$

여기서, $1_{d}^{k}, 1_{d}^{l}=$ 위성 $k, l$ 의 단위시선벡터

$$
|e|=\vec{e}_{d b} \text { 의 길이 }
$$

$\phi_{k}, \phi_{l}, \phi_{b}=$ 위성 $k, l$ 및 추정위치의 각도

수식 (7)에서 미지정수 $N_{d b}^{k l}$ 의 범위는 검색범위 내 임의의 위치에 대한 각도 $\phi_{b}$ 가 임의이므로 수 식 (8)과 같이 유도할 수 있다.

$-2|e|_{\max } \sin \left(\frac{\Delta \phi}{2}\right) \leq N_{d b}^{k l} \leq 2|e|_{\max } \sin \left(\frac{\Delta \phi}{2}\right)$

위 수식에서 미지정수 검색범위는 위성사이의 각도 $\triangle \phi$ 에 비례한다. 위성사이의 각도는 다음 수식 (9)와 같이 단위 시선벡터의 내적 개념을

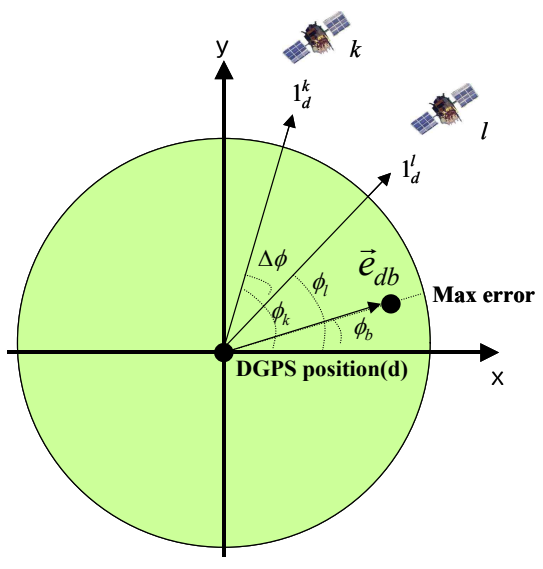

그림 4. 사이각 $\Delta \phi$ 도시 
적용하면 적은 계산량으로 구해지므로, 추적하고 있는 모든 위성들의 사이각도를 계산하는 것은 어렵지 않다.

$$
1 \times 1 \times \cos (\triangle \phi)=x_{k} x_{l}+y_{k} y_{l}+z_{k} z_{l}
$$

여기서,

$$
\begin{aligned}
& \left(x_{k}, y_{k}, z_{k}\right)=\text { 단위시선벡터 } 1_{d}^{k} \text { 의 } 3 \text { 차원좌표 } \\
& \left(x_{l}, y_{l}, z_{l}\right)=\text { 단위시선벡터 } 1_{d}^{l} \text { 의 } 3 \text { 차원좌표 }
\end{aligned}
$$

위의 기준으로 주위성을 선택할 경우 앙각순 으로 선택할 경우보다 장시간의 데이터 분석결과 평균 $50 \%$ 정도 미지정수 조합이 감소하여 실시 간으로 미지정수를 추정해야 할 경우 유리하다 [9]. 또한 일정한 개수의 미지정수를 추정할 경우 에는 더욱 넓은 위치영역에 대해서 미지정수 검 색을 수행한다고 볼 수 있으므로 신뢰도도 좋아 진다고 할 수 있다. 그러나 사이각이 작은 순서 대로 주위성을 선택할 경우 위성이 집중적으로 존재할 수 있고 기하학적인 상대위치 정확도 즉 RDOP(Relative Delusion Of Precision)이 커질 수 있다. 따라서 $\mathrm{RDOP}$ 이 한계치 이상으로 커질 경우 주위성 선택을 다시 해야 한다. RDOP은 다음 수식(10)과 같이 PDOP(Position Delusion Of Precision)으로 계산된다[10]. RDOP의 한계치 는 반송파 위상측정 정확도를 $0.01 \mathrm{~m}$ 로 고려할 때, 주위성에 의한 위치오차를 $1 / 4$ 파장 $(0.05 \mathrm{~m})$ 이내로 추정하기 위해서 5 로 정하였다.

$$
R D O P=\sqrt{2} \times P D O P
$$

본 논문에서는 또한 이동국 단독으로 모든 위 성의 반송파 위상으로부터 계산된 1 초당 이동거 리인 평균속도를 적분하여 위치를 추정한 후 CDGPS에 의한 위치를 재검증하는 방안을 제시 하였다. 이러한 평균속도의 정확도는 원자시계로 동기되어 있는 위성의 반송파 위상 차분을 이용 하기 때문에 CDGPS 위치정확도 차분과 거의 동 일한 수 $\mathrm{cm} / \mathrm{s}$ 이다. 위와같이 이동국에서 독립적 으로 측정되는 평균속도를 이용하면 미지정수 추 정기법의 최대단점인 신뢰도 문제를 보완할 수 있고, 일정시간 기준국의 상태에 상관없이 정확 한 위치를 추정할 수 있다는 장점이 있다.

\section{IV. 시험결과}

\section{1 정적시험}

제안한 미지정수 추정기법을 검증하기 위해서 기준국과 이동국을 측지점에 고정시키고, CDGPS 기법으로 상대위치를 측정하였다. 본 논문에서
사용한 GPS 수신기는 DGPS에서 가장 큰 오차 요인인 의사거리의 다중경로 오차를 효과적으로 감소시킬 수 있는 스트로브(Strobe) 상관기를 적 용한 그림 5 의 단일주파수 GPS 수신기이다. 기 준국과 이동국의 길이인 기저선 길이는 $5 \mathrm{~m}$ 이며, 기준국 안테나는 다중경로의 영향을 줄여주는 Novatel사의 GPS-503 쵸크링 안테나, 이동국 안 테나는 Novatel사의 GPS-600 안테나이다.

3600 여초 동안 위성위치, 위성속도, 의사거리, 반송파 위상 등의 데이터를 획득한 후 사후처리 하였다. 추적위성은 7 9개, $\mathrm{PDOP}$ 은 1.0 2.4의 값 을 보였으며, 그림 6,7 과 같이 DGPS는 $1.9 \mathrm{~m}$ $2 \mathrm{drms}, \mathrm{CDGPS}$ 는 $0.01 \mathrm{~m} 2 \mathrm{drms}$ 의 정확도를 보였 다.

정적시험 결과, 논문에서 제안한 주위성의 최 소사이각 선택기법에 의해서 미지정수 후보군이 LSAST의 앙각순으로 선택할 때의 3705개에서 2475 개로 감소했다. 미지정수 후보군에 대한 모 든 잔차를 매 epoch마다 계산하고, 잔차가 가장 작은 미지정수부터 $75 \%$ 신뢰도의 Chi Square 기 준 이하로 일정시간(300 epoch) 유지된 후 누적 잔차를 비교하는 비율검사(3배)로 확정하였다. 미

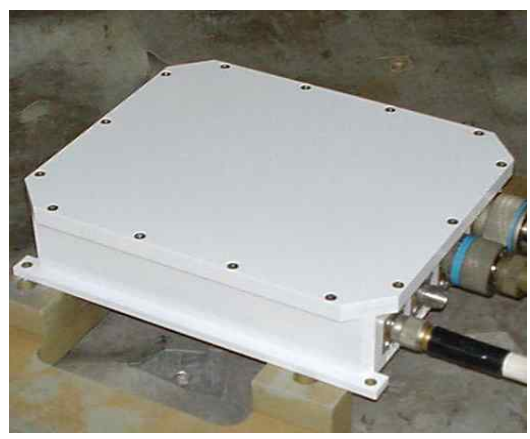

그림 5. 스트로브 GPS 수신기

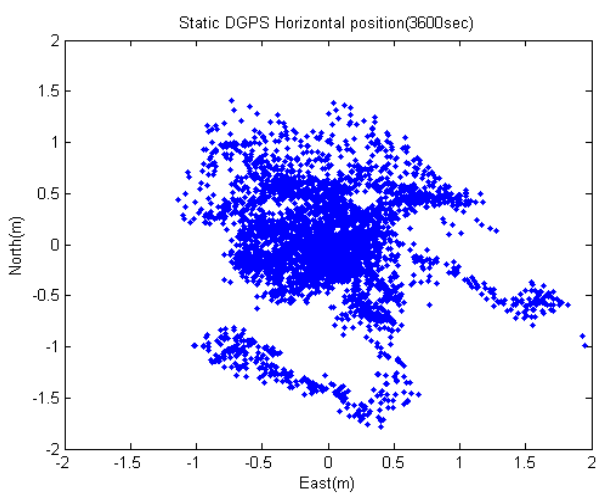

그림 6. DGPS로 측정한 상대위치 


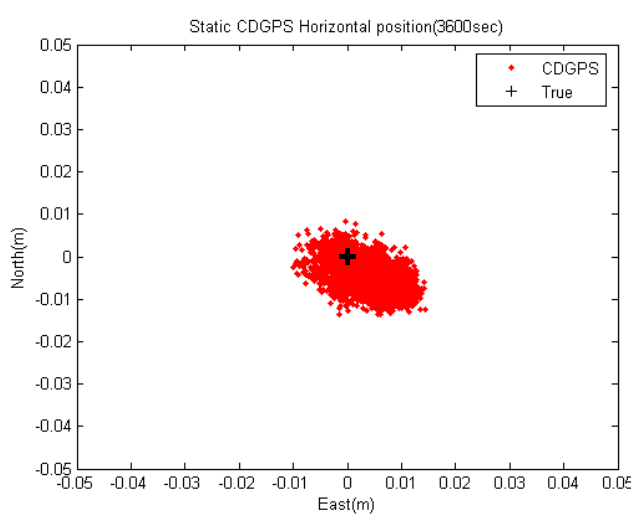

그림 7. CDGPS로 측정한 상대위치

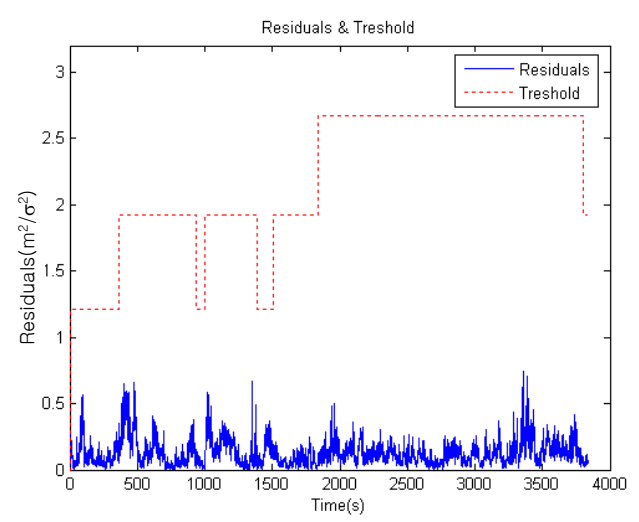

그림 8. 정적시험의 잔차(Residuals)

지정수 후보군이 3705 개인 경우 83 번째, 2475 개 인 경우 14 번째로 작은 잔차를 첫 epoch에서 가 진 미지정수가 참값이었으며 측지점과 일치하였 다. 따라서 제안한 미지정수 추정기법에 의해서 상대적으로 적은 미지정수 후보군에서 미지정수 를 검색하므로 실시간으로 미지정수를 추정해야 할 경우 계산량이 줄어 유리하다. 또한 미지정수 후보군 수를 동일하게 검색한다면, 수식(8)의 DGPS 최대 오차범위인 $|e|_{\max }$ 가 커져 넓은 영역 에서 미지정수를 검색하므로 신뢰도가 높아진다 고 할 수 있다. 그림 8에서 알 수 있듯이 미지정 수가 참값이면 반송파 위상 측정치의 분산 $\left(\sigma^{2}\right)$ 으 로 나눈 잔차는 Chi Square 임계치(자유도=위성 수-4)보다 작은 값으로 계속 유지된다.

\section{2 차량시 험}

이동하는 항체에 대해 본 논문에서 제안한 CDGPS 기법으로 상대위치를 수 $\mathrm{cm}$ 정확도로 측정하기 위해서 차량시험을 수행하였다.

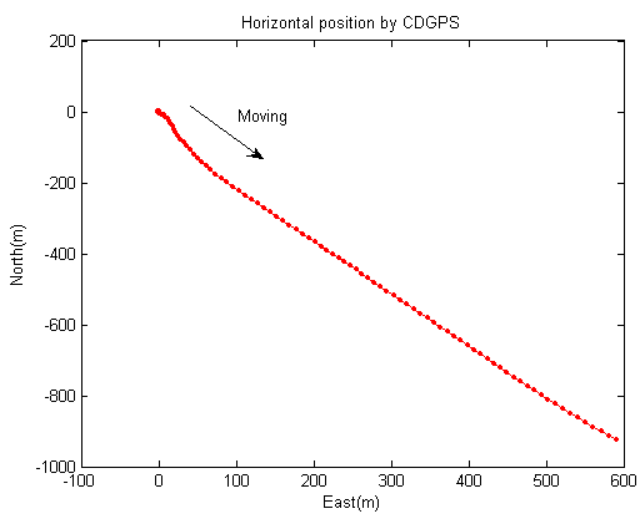

그림 9. CDGPS로 측정한 차량 위치

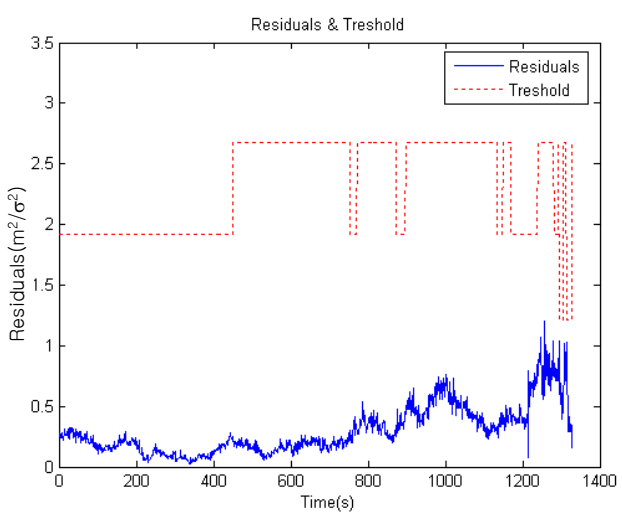

그림 10. 차량시험의 잔차(Residuals)

초기 정지상태에서 기준국과 이동국의 기저선 길이는 약 $2 \mathrm{~km}$ 이고, 1200 초 정지한 후 170 초 동 안 약 $1.2 \mathrm{~km}$ 를 움직인 차량시험을 분석한 결과, CDGPS에 의해서 그림 9 와 같은 위치가 측정되 었다. 차량시험 결과도 정적시험과 마찬가지로, 본 논문에서 제안한 미지정수 추정기법에 의해서 미지정수 후보군이 5704개에서 3128 개로 줄어들 어 연산량이 줄었다. 또한 미지정수 후보군이 5704 개인 경우 첫 epoch에서 528번째 작은 잔차 가 참값의 미지정수이고, 3128 개인 경우 363 번째 작은 잔차가 참값이었다. 그림 10 에서 분산으로 나눈 잔차는 임계치 이하로 계속 유지되었다.

CDGPS로 측정된 위치를 비교하기 위해 초기 오차가 매우 작은 $1 \mathrm{mile}$ 급 INS를 이용하였는데, 3 분후 대략 $1 \mathrm{~m}(1 \sigma)$ 정도의 오차를 가진다. INS의 위치와 비교하면 그림 11 과 같은데, 15 90초 구 간은 차량이 회전할 때 GPS 안테나와 INS의 장 착위치 차이에 의한 지렛대(Lever Arm) 효과에 의하여 위치 차이를 보였다. 초기에는 위치차이 

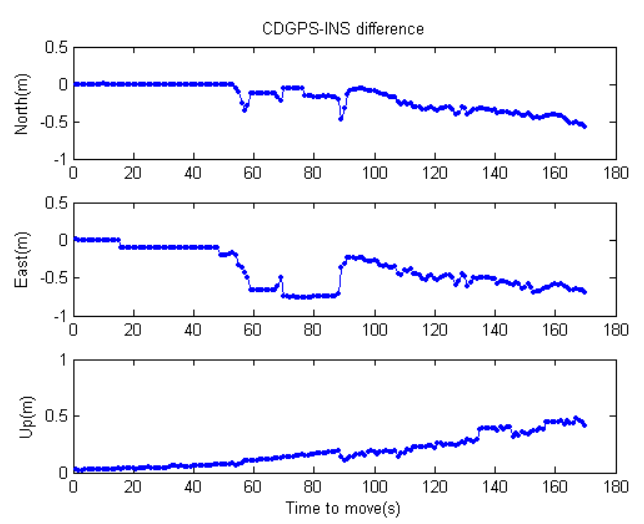

그림 11. INS와 비교한 위치차이

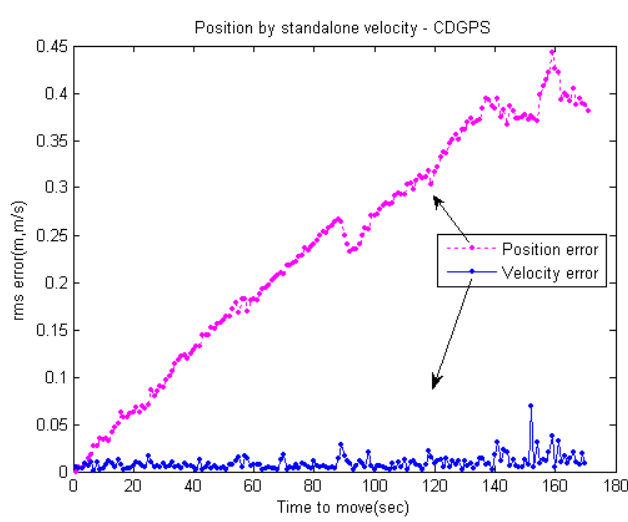

그림 12. 평균속도로 추정한 3 차원 위치오차

가 수 $\mathrm{cm}$ 이하이므로 CDGPS의 위치를 검증할 수 있었으나, 시간이 지나면서 INS의 특징에 따 라 INS의 위치오차가 증가함을 알 수 있다.

반송파 위상으로 계산한 평균속도를 이용하여 추정된 위치는 CDGPS 위치에 비해, 그림 12와 같이 170 초에 $0.4 \mathrm{~m}$ 의 오차를 가졌으며, 평균속도 오차는 수 $\mathrm{cm} / \mathrm{s}$ 로 정확하였다. 따라서 평균속도 에 의한 위치는 CDGPS의 위치 검증에 쓰일 수 있고, 단독으로 20 초 내에는 반송파의 반파장인 $0.1 \mathrm{~m}$ 이하의 위치를 제공할 수 있다.

\section{V. 결 론}

본 논문에서는 CDGPS에서 가장 중요한 미지 정수 추정기법을 개선하여 계산효율 및 신뢰도를 높이고, GPS 수신기를 이용하여 움직이는 항체의
상대위치를 수 $\mathrm{cm}$ 내의 정확도로 측정한 실험결 과를 제시하였다. 반송파 위상으로 계산된 평균 속도를 이용하여 추정한 위치와 CDGPS에 의해 추정한 위치를 비교하여 다시 한번 검증하였으 며, 정밀한 INS의 위치와 비교하여 분석한 결과 Lever Arm 효과를 확인하였다. 이러한 결과는 추 후 정밀관성항법장치, 측지, 정밀지도제작 등에 유용하게 쓰일 수 있다.

\section{참고문헌}

1) Elliot. D. Kaplan, Understanding GPS Principles and Applications, Artech House, 1996.

2) Hatch, R. "Instantaneous Ambiguity Resolution", Proceedings of KIS'90, Banff, Canada, 10-13 September, 1990, pp. 299-308.

3) Teunissen, P.J.G, "A New Method for Fast Carrier Phase Ambiguity Estimation", Proceedings of IEEE PLANS, Las Vegas, 1994, pp. 562-573.

4) 신용설, 박찬국, "시계 바이어스 변화율을 이용한 반송파 DGPS의 성능 향상", 한국항공우 주학회지, 제 33권 12호, 2005, pp. 61-67.

5) DOD, NAVSTAR GPS User Equipment Introduction(Public Release Version), GPS Joint Program Office, February, 1991.

6) Pratap Misra, Per Enge, GLOBAL POSITIONING SYSTEM Signals, Measurements, and Performance, Ganga-Jamuna Press, 2001.

7) Taikjin Lee, Haeyoung Jun, Doohee Yun and Changdon Kee, "Outdoor Navigation System Using Pseudolites", ION GNSS 17th Technical Meeting of the Satellite Division, Long Beach, 2004, pp. 1948-1958.

8) 유호, 이은성, 이영재, 지규인, 남기욱, 전향 식, "GPS 반송파의 시간차분 특성", 한국항공우 주학회지, 제 33권, 9호, 2005, pp. 66-72

9) 이기훈, 김준오, 안승관, 백복수, “GPS를 이 용한 3차원 실시간 자세측정에 관한 연구", 제 10차 GNSS Workshop, 21-22 November, 2003.

10) Chansik Park, "Comments on "Relationships Between Dilution of Precision for Point Positioning and for Relative Positioning with GPS", IEEE Transactions on Aerospace and Electronic Systems, Vol. 36, no. 1, January, 2000. 